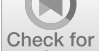

updates

Cite as

Nano-Micro Lett.

(2022) $14: 51$

Received: 6 December 2021

Accepted: 30 December 2021

Published online: 27 January 2022

(C) The Author(s) 2022

\section{High-Efficiency Electromagnetic Interference Shielding of rGO@FeNi/Epoxy Composites with Regular Honeycomb Structures}

\author{
Ping Song ${ }^{1}$, Zhonglei Ma ${ }^{1} \bowtie$, Hua Qiu ${ }^{1}$, Yifan $\mathrm{Ru}^{2}$, Junwei Gu ${ }^{1} \bowtie$
}

\title{
HIGHLIGHTS
}

- The rGH@FeNi/epoxy electromagnetic interference (EMI) shielding composites with regular 3D honeycomb structures were prepared by sacrificial template, freeze-drying and vacuum-assisted impregnation of epoxy resin.

- The construction of 3D honeycomb structure and electromagnetic synergistic effect significantly increase the EMI shielding effectiveness and reduce the secondary contamination.

- The rGH@FeNi/epoxy composites possess excellent thermal stability and mechanical properties.

ABSTRACT With the rapid development of fifth-generation mobile communication technology and wearable electronic devices, electromagnetic interference and radiation pollution caused by electromagnetic waves have attracted worldwide attention. Therefore, the design and development of highly efficient EMI shielding materials are of great importance. In this work, the three-dimensional graphene oxide (GO) with regular honeycomb structure $(\mathrm{GH})$ is firstly constructed by sacrificial template and freeze-drying methods. Then, the amino functionalized FeNi alloy particles $(f-\mathrm{FeNi})$ are loaded on the GH skeleton followed by in-situ reduction to prepare rGH@FeNi aerogel. Finally, the rGH@FeNi/epoxy EMI shielding composites with regular honeycomb structure is obtained by vacuum-assisted impregnation of epoxy resin. Benefitting from the construction of regular honeycomb structure and electromagnetic synergistic effect, the rGH@ FeNi/epoxy composites with a low rGH@FeNi mass fraction of 2.1 wt\%

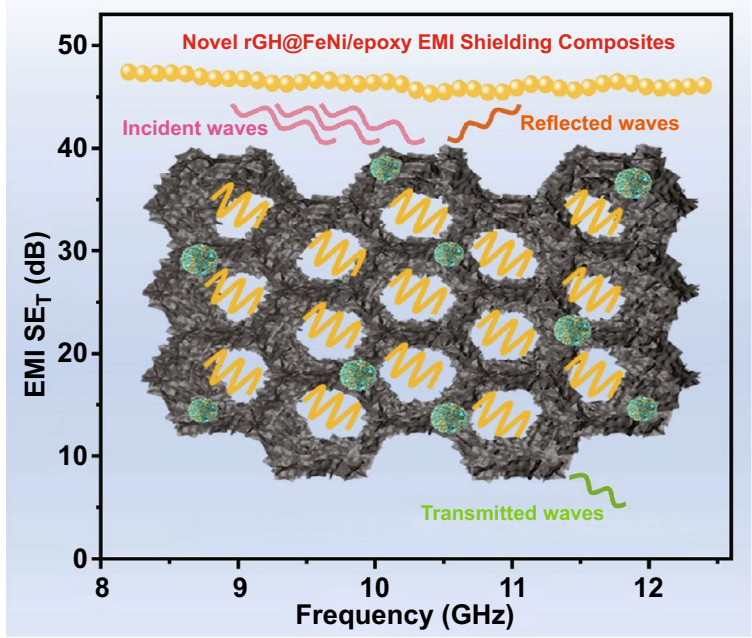
(rGH and $f$-FeNi are 1.2 and $0.9 \mathrm{wt} \%$, respectively) exhibit a high EMI shielding effectiveness (EMI SE) of $46 \mathrm{~dB}$, which is 5.8 times of that $(8 \mathrm{~dB})$ for $\mathrm{rGO} / \mathrm{FeNi} /$ epoxy composites with the same rGO/FeNi mass fraction. At the same time, the rGH@FeNi/epoxy composites also possess excellent thermal stability (heat-resistance index and temperature at the maximum decomposition rate are 179.1 and $389.0{ }^{\circ} \mathrm{C}$ respectively) and mechanical properties (storage modulus is $8296.2 \mathrm{MPa}$ ).

KEYWORDS Electromagnetic interference shielding; rGO@FeNi; Epoxy resins; Honeycomb structures

Zhonglei Ma, mazl@nwpu.edu.cn; Junwei Gu, gjw@nwpu.edu.cn; nwpugjw@163.com

1 Shaanxi Key Laboratory of Macromolecular Science and Technology, School of Chemistry and Chemical Engineering, Northwestern Polytechnical University, Xi' an 710072, People's Republic of China

2 Queen Mary University of London Engineering School, Northwestern Polytechnical University, Xi'an 710072, People's Republic of China 


\section{Introduction}

With the rapid development of fifth-generation (5G) communication technology and wearable electronic devices, electromagnetic interference (EMI) and radiation pollution caused by electromagnetic waves have become prominent issues in consumer electronics, artificial intelligence and information security, etc. The leakage of electromagnetic waves will not only cause malfunctioning issues of electronic communication equipment and its delicate components, but also pose serious threats to human health [1-4]. Polymer-based EMI shielding composites have become an important research direction of efficient EMI shielding materials due to their advantages of light weight, corrosion resistance, stable EMI shielding performance and outstanding mechanical properties [5-7].

Currently, polymer-based EMI shielding composites mainly achieve their excellent EMI shielding performances by incorporating conductive and/or magnetic functional fillers into polymer matrix. Commonly used polymer matrixes include natural rubber (NR), polyethylene (PE), polypropylene (PP), polyurethane (PU), polyvinylidene fluoride (PVDF), polyimide (PI) and epoxy resins, etc. [8-10]. The conductive fillers usually include metals, conductive polymers and carbon materials. Among them, carbon materials such as carbon black, graphite, carbon fiber, carbon nanotubes (CNTs) and reduced graphene oxide ( $\mathrm{rGO}$ ) have attracted extensive attention due to their advantages of low density, high electrical conductivity $(\sigma)$, corrosion resistance and easy processing [11-13]. The rGO, especially, has been widely used in EMI shielding due to its unique twodimensional lamellar structure, excellent $\sigma$ and outstanding mechanical properties [14-16]. However, rGO tends to agglomerate in polymer matrix and has a large contact resistance, resulting in the relatively high conductive percolation threshold of polymer-based composites [17, 18]. Therefore, high rGO mass fraction is usually required to obtain excellent EMI shielding performance, which greatly affects the mechanical properties and processabilities of the composites [19].

The construction of efficient three-dimensional (3D) conductive networks can effectively reduce the percolation threshold of rGO/polymer composites, so as to realize the synergistic improvement of $\sigma$, EMI shielding performances and mechanical properties for polymer composites at low filler content [20,21]. Current methods for constructing efficient 3D conductive networks in polymer-based composites mainly include foaming, surface coating-hot pressing and sol-gel methods, etc. [22]. Eswaraiah et al. [23] reported the fabrication of functionalized rGO/PVDF foam composites using 2,2'-azobiso-butanitrile (AIBN) as the chemical foaming agent. The resultant rGO/PVDF foam composites had an EMI shielding effectiveness (EMI SE) of $28 \mathrm{~dB}$ when the rGO mass fraction was $7 \mathrm{wt} \%$. Yan et al. [24] fabricated the rGO/PS EMI shielding composites with segregated structure by dip-coating rGO onto the surface of PS particles followed by hot pressing them together. The EMI SE of rGO/ PS composites reached $45 \mathrm{~dB}$ when the rGO volume fraction was 3.47 vol\%. In our previous work, Gu et al. [25] firstly prepared the graphite nanoplatelets (GNPs)/rGO aerogel by sol-gel method, and then obtained the GNPs/rGO/epoxy EMI shielding composites by vacuum-assisted impregnation of epoxy resin. The results show that the EMI SE of GNPs/rGO/epoxy nanocomposites reached $51 \mathrm{~dB}$ when the rGO and GNPs mass fractions were 0.1 and $20.4 \mathrm{wt} \%$, respectively.

Although the constructed 3D conductive networks can endow the polymer composites with excellent $\sigma$ and EMI shielding performances at low filler content, the conductive networks obtained by the above methods have poor structural regularity and the distribution of nanofillers is not easy to control, leading to the poor stability of $\sigma$ and EMI shielding performances $[26,27]$. The rGO conductive networks with honeycomb structure based on alumina $\left(\mathrm{Al}_{2} \mathrm{O}_{3}\right)$ honeycomb plates possess the advantages of regular morphology, and controllable size, shape and distribution of holes, as well as good repeatability and stability. In our previous work, $\mathrm{Gu}$ et al. [28] used $\mathrm{Al}_{2} \mathrm{O}_{3}$ honeycomb plates as templates to prepare the rGO with regular honeycomb structure (rGH)/epoxy EMI shielding composites by sacrificial template, freeze-drying and vacuum-impregnation methods. The obtained $\mathrm{rGH} /$ epoxy composites at a mass fraction of 1.2 wt $\%$ rGH exhibit an elevated EMI SE value of $38 \mathrm{~dB}$, which was 6.3 times of that of the homogeneously blended $\mathrm{rGO} /$ epoxy composites at the same rGO mass fraction.

In addition, the EMI shielding mechanism of the existing polymer-based composites is mainly based on conduction loss, and the impedance mismatch between their surface and air results in the reflections of electromagnetic waves on the surface of composites, which is easy to cause the secondary electromagnetic wave pollution [29,30]. Studies have shown 
that the introduction of magnetic materials can improve the impedance match between the composites and external space, thus reducing the reflections of electromagnetic waves and secondary contamination [31-33]. The magnetic materials mainly include pure metal (iron, cobalt and nickel, etc.), metal oxides (iron oxide, ferrite and nickel oxide, etc.) and metal alloys (iron-cobalt alloy, iron-nickel alloy and cobalt-nickel alloy, etc.). FeNi alloy exhibits excellent initial permeability, relative permeability, as well as low coercivity and repeated magnetization loss, and shows great potentials in EMI shielding applications [34-36].

In this paper, $\mathrm{Al}_{2} \mathrm{O}_{3}$ honeycomb plates were used as templates to construct $\mathrm{GO}$ with regular honeycomb structure (GH) by sacrificial template and freeze-drying. Then, the surface functionalized $\mathrm{FeNi}$ alloy particles $(f$-FeNi) were loaded on the GH aerogel and reduced in situ to prepare magnetic and conductive rGH@FeNi aerogel Finally, rGH@ FeNi/epoxy EMI shielding composites with regular honeycomb structure were obtained by vacuum-assisted impregnation of epoxy resin and high temperature curing. The chemical structures of $f$-FeNi, rGH, and rGH@FeNi were characterized and analyzed by X-ray diffraction (XRD), Raman spectroscopy, X-ray photoelectron spectroscopy (XPS) and physical property measurement system (PPMS). The microstructures of rGH@FeNi aerogel and rGH@ FeNi/epoxy composites were observed by scanning electron microscope (SEM). On this basis, the effects of regular honeycomb structure and $f$-FeNi loading on electrical conductivities $(\sigma)$, EMI SE, thermal stability and mechanical properties of rGH@FeNi/epoxy composites were detailedly investigated.

\section{Experimental}

\subsection{Preparation of rGH@FeNi Aerogel}

The GH aerogel was prepared according to our previous work [28]. The microporous $\mathrm{Al}_{2} \mathrm{O}_{3}$ honeycomb plate (pore size $500 \mu \mathrm{m}$ ) was firstly placed in $10 \mathrm{~g} \mathrm{~L}^{-1} \mathrm{GO}$ solution prepared by oxidative exfoliation of graphite flakes [37]. Subsequently, $\mathrm{GO}$ was completely filled in the $\mathrm{Al}_{2} \mathrm{O}_{3}$ honeycomb lattice by vacuum degassing. After standing for $48 \mathrm{~h}$, it was frozen in $-25^{\circ} \mathrm{C}$ refrigerator, and then freeze-dried for $48 \mathrm{~h}$ to obtain $\mathrm{GO}-\mathrm{Al}_{2} \mathrm{O}_{3}$ honeycomb composite structure. Then, it was placed in dilute hydrochloric acid $(\mathrm{HCl})$ to remove the
$\mathrm{Al}_{2} \mathrm{O}_{3}$ honeycomb plate, and the $\mathrm{GH}$ aerogel was obtained by freeze-drying for $48 \mathrm{~h}$ after repeated washing with deionized (DI) water to remove the residual dilute $\mathrm{HCl}$.

FeNi alloy particles $(2 \mathrm{~g})$ and ammonium persulfate (APS, $1 \mathrm{~g}$ ) were added into $100 \mathrm{~mL}$ DI and mechanically stirred for $30 \mathrm{~min}$. After stirring at $70{ }^{\circ} \mathrm{C}$ for $30 \mathrm{~min}$, acrylic acid (AA, $10 \mathrm{~mL}$ ) was added into the FeNi dispersion and stirred for $3 \mathrm{~h}$. Ethylenediamine (EN, $20 \mathrm{~mL}$ ) was added into the above mixture drop by drop and continuously stirred for $3 \mathrm{~h}$. The product was washed for several times with DI water until the $\mathrm{pH}$ was about 7 . After drying, the $f$-FeNi alloy particles were prepared.

$f$-FeNi was placed in DI water and mechanically stirred for $30 \mathrm{~min}$ to form a homogeneous dispersion. $\mathrm{GH}$ aerogel was placed in the obtained dispersion with slow stirring for $30 \mathrm{~min}$, and then heated to $60^{\circ} \mathrm{C}$ with continuous stirring for $2 \mathrm{~h}$. GH@FeNi aerogel was obtained by freezedrying for $48 \mathrm{~h}$. The GH@FeNi aerogel was annealed under $5 \%$ hydrogen/argon (V/V) atmosphere at $600{ }^{\circ} \mathrm{C}$ for 2 h to obtain rGH@FeNi aerogel.

\subsection{Preparation of rGH@FeNi/epoxy Composites}

Epon 862 bisphenol $\mathrm{F}$ epoxy resin and EK3402 curing agent $(100 / 26.5, \mathrm{~W} / \mathrm{W})$ were mixed and mechanically stirred at $70{ }^{\circ} \mathrm{C}$ for $30 \mathrm{~min}$ to obtain a uniform mixture. The mixture was then poured into a mold containing rGH@FeNi aerogel, followed by vacuum-assisted degassing to remove air bubbles. The rGH@FeNi/epoxy EMI shielding composites were obtained by curing at $120{ }^{\circ} \mathrm{C}$ for $5 \mathrm{~h}$. Schematic diagram of the fabrication for rGH@ $\mathrm{FeNi}$ /epoxy composites is shown in Fig. 1. The mass fractions of fillers in rGH@FeNi/epoxy composites are shown in Table 1. For comparison, $\mathrm{rGO} / \mathrm{FeNi}$ /epoxy EMI shielding composites with the same $\mathrm{rGO} / \mathrm{FeNi}$ mass fraction were prepared by direct blending.

\section{Results and Discussion}

\subsection{Characterizations of rGH, $f$-FeNi, GH@ FeNi and rGH@FeNi}

Figure S1a shows the magnetic variation curves of $\mathrm{rGH}$, $f$-FeNi and rGH@FeNi aerogels. It can be seen that $f$-FeNi 


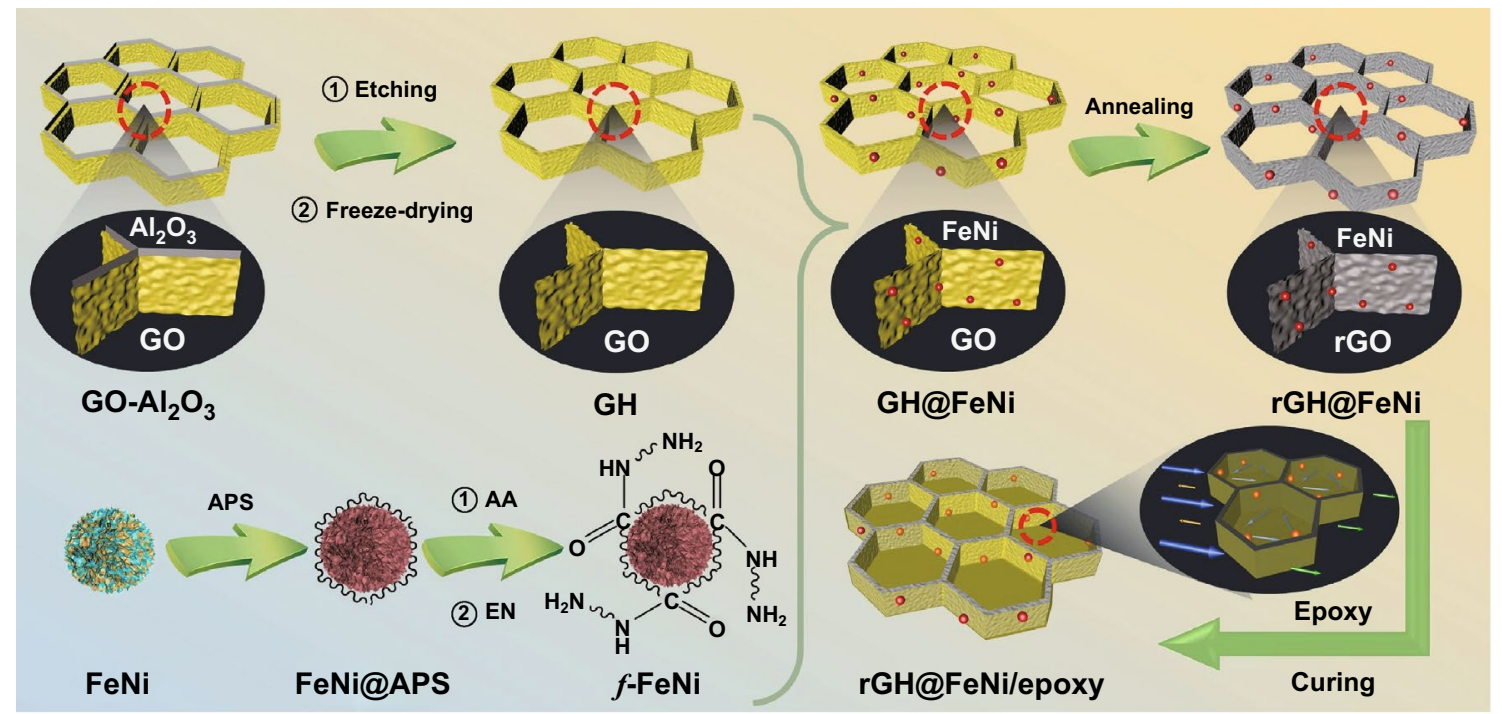

Fig. 1 Schematic diagram of the fabrication for rGH@FeNi/epoxy composites

shows excellent magnetic properties with saturation magnetization of $113.6 \mathrm{emu} \mathrm{g}^{-1}$, while $\mathrm{rGH}$ is nonmagnetic. The hysteresis loop of rGH@FeNi aerogel exhibits typical superparamagnetism [38], with a saturation magnetization of $48.7 \mathrm{emu}^{-1}$, which is slightly lower than that of $f$-FeNi. The calculated mass fraction of $f$-FeNi accounts for $43 \%$ of the total filler mass, which is consistent with the experimental design scheme. Figure S1b further shows that the rGH@ FeNi aerogel has excellent magnetic properties.

Figure 2 is XRD (a), Raman (b) and XPS (c) spectra of $f$-FeNi, GH@FeNi and rGH@FeNi aerogels. FeNi and $f$-FeNi both present the same characteristic diffraction peak positions in XRD spectra (Fig. S2), indicating that the amino functionalized modification did not change the crystal phase structure of FeNi. The diffraction peaks at $43.6^{\circ}$ and $50.8^{\circ}$ correspond to (111) and (200) crystal planes of $\alpha$-Fe in $f$-FeNi cubic respectively, and the diffraction peak at $5.3^{\circ}$ corresponds to (220) crystal plane of $f$-FeNi facecentered cubic Ni [39]. In XRD spectrum of GH@FeNi aerogel, the characteristic diffraction peak at $9.9^{\circ}$ corresponds to (001) crystal plane of GO. No obvious GO diffraction peak was observed in XRD spectrum of rGH@ FeNi aerogel, but a broad and weak characteristic diffraction peak of rGO appears at $26.0^{\circ}$, implying that the GH has been completely reduced to $\mathrm{rGH}[40,41]$. The XRD pattern of rGH@FeNi aerogel also shows the characteristic diffraction peak of $f$-FeNi, indicating that rGH@FeNi aerogel can retain the crystal phase structure of rGO and $f$-FeNi
Table 1 Filler mass fraction of rGH@FeNi/epoxy composites

\begin{tabular}{llll}
\hline Samples & $\begin{array}{l}\text { rGH@FeNi } \\
\text { (wt\%) }\end{array}$ & rGH (wt\%) & $\begin{array}{l}f \text {-FeNi } \\
\text { alloy } \\
\text { (wt\%) }\end{array}$ \\
\hline Pure epoxy & 0 & 0 & 0 \\
1.2 wt\% rGH@FeNi/epoxy & 1.2 & 1.2 & 0 \\
1.5 wt\% rGH@FeNi/epoxy & 1.5 & 1.2 & 0.3 \\
1.8 wt\% rGH@FeNi/epoxy & 1.8 & 1.2 & 0.6 \\
2.1 wt\% rGH@FeNi/epoxy & 2.1 & 1.2 & 0.9 \\
2.4 wt\%rGH@FeNi/epoxy & 2.4 & 1.2 & 1.2 \\
\hline
\end{tabular}

completely. All Raman spectra show the D-band around $1343 \mathrm{~cm}^{-1}$ and G-band around $1589 \mathrm{~cm}^{-1}$. The intensity ratios of D-band and G-band $\left(\mathrm{I}_{\mathrm{D}} / \mathrm{I}_{\mathrm{G}}\right)$ for $f$-FeNi, GH@FeNi and rGH@FeNi aerogels are 0.84, 0.89, and 1.02, respectively, which is because that the introduction of $f$-FeNi and reduction of GO will increase defect degree of GH. The proper defect and graphitization degree can improve the impedance matching with enhanced polarization relaxation and dipole relaxation, which is beneficial to the attenuation of electromagnetic waves [36]. All XPS spectra show the characteristic absorption peaks of $\mathrm{C} 1 \mathrm{~s}, \mathrm{~N} 1 \mathrm{~s}$, and $\mathrm{O}$ $1 \mathrm{~s}$ at $284.8,398.8$, and $531.8 \mathrm{eV}$. The GH@FeNi aerogel presents characteristic absorption peaks of $\mathrm{Fe} 2 \mathrm{p}$ and $\mathrm{Ni}$ $2 p$ at 710.8 and $854.8 \mathrm{eV}$, respectively, indicating that the $f$-FeNi is successfully grafted on the surface of $\mathrm{GH}$. The $\mathrm{C} / \mathrm{O}$ value of rGH@ FeNi is increased significantly from 1.7 to 8.1, confirming the complete reduction of GH@FeNi [42], 

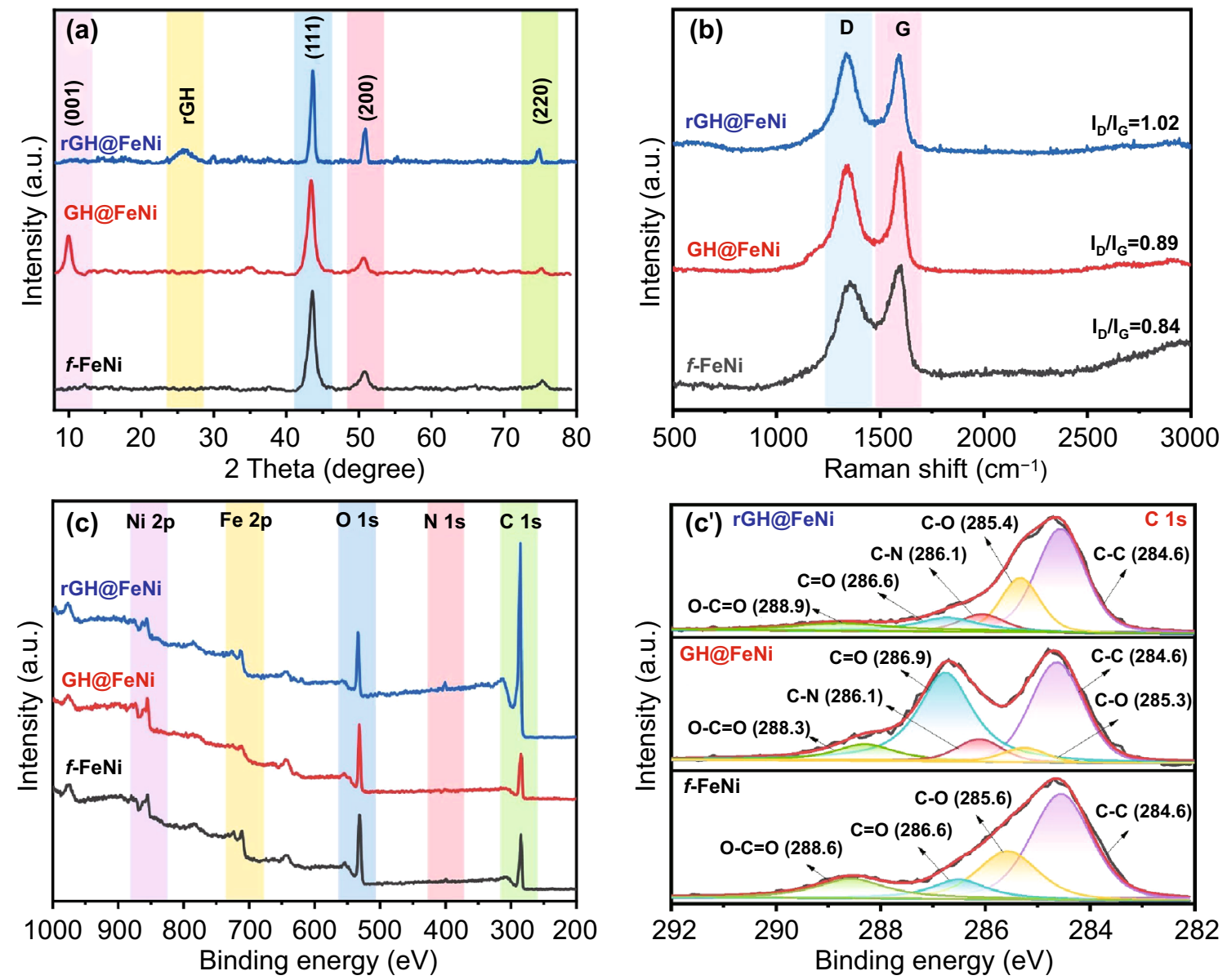

Fig. 2 XRD (a), Raman (b), XPS spectra (c) and high-resolution C 1 s (c' $\left.{ }^{\prime}\right)$ of $f$-FeNi, GH@FeNi and rGH@FeNi aerogel (rGH 1.2 wt $\%, f$-FeNi $0.9 \mathrm{wt} \%)$

which is consistent with the XRD results. Figure 2c' shows the high-resolution C 1 s spectra of $f$-FeNi, GH@FeNi and rGH@FeNi aerogel. It can be seen that the high-resolution C $1 \mathrm{~s}$ spectrum of $f$-FeNi presents four characteristic peaks at 284.6, 285.6, 286.6, and $288.6 \mathrm{eV}$ corresponding to unoxidized carbon $(\mathrm{C}-\mathrm{C})$, carbon in hydroxyl and epoxy groups (C-O), carbon in carbonyl group $(\mathrm{C}=\mathrm{O})$, and carbon in carboxyl group $(\mathrm{O}-\mathrm{C}=\mathrm{O})$, respectively. After grafting of $f$-FeNi on $\mathrm{GH}$ surface, the high-resolution $\mathrm{C} 1 \mathrm{~s}$ spectrum of GH@ FeNi aerogel shows a characteristic peak of C-N at $286.1 \mathrm{eV}$, which is attributed to the generated C-N bond by condensation reaction between $-\mathrm{NH}_{2}$ on $f$-FeNi and $-\mathrm{COOH}$ on $\mathrm{GH}$. The results demonstrate that the $f$-FeNi has been successfully grafted on the surface of GH skeleton. The peak intensity of oxygen-containing functional groups decreased significantly after thermal annealing, indicating that the
GH@FeNi aerogel has been successfully reduced to rGH@ FeNi aerogel $[43,44]$.

\subsection{Morphologies of rGH@FeNi Aerogel and rGH@ FeNi/epoxy Composites}

Figure 3 shows SEM images of rGH@FeNi aerogel and rGH@FeNi/epoxy composites. As can be seen from Fig. 3a, a', the rGH@FeNi aerogel presents anisotropic structures with highly regular hexagonal honeycomb structure in cross section and highly oriented prismatic structure in longitudinal sections. The side length of honeycomb cells is about $500 \mu \mathrm{m}$. When the $\mathrm{Al}_{2} \mathrm{O}_{3}$ template is immersed in GO solution, the surface of $\mathrm{Al}_{2} \mathrm{O}_{3}$ template is ionized with released $\mathrm{Al}^{3+}$ spontaneously 


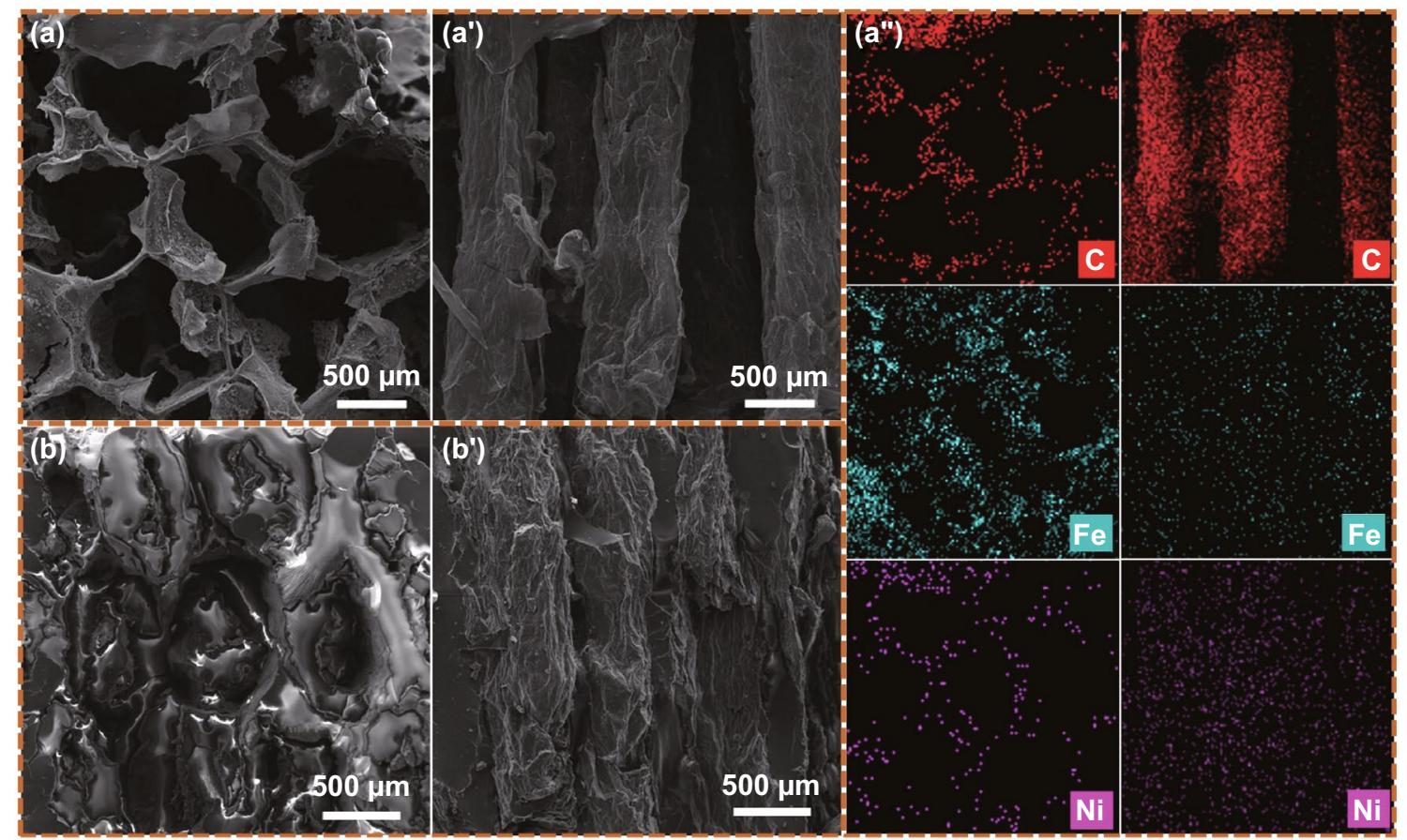

Fig. 3 SEM images of rGH@FeNi aerogel (rGH 1.2 wt $\%, f$-FeNi 0.9 wt $\%$ ) along the cross and longitudinal sections (a \& a'), elemental mapping images of $\mathrm{C}, \mathrm{Fe}$ and Ni for rGH@FeNi aerogel (a"), SEM images of rGH@FeNi/epoxy composites (rGH 1.2 wt $\%$, f-FeNi 0.9 wt\%) along the cross and longitudinal sections $\left(\mathbf{b} \& \mathbf{b}^{\prime}\right)$

diffused into the weakly acidic GO solution. This significantly increases the ionic strength near $\mathrm{Al}_{2} \mathrm{O}_{3}$ template and causes the negatively charged $\mathrm{GO}$ nanosheets to aggregate on the $\mathrm{Al}_{2} \mathrm{O}_{3}$ template and form GO hydrogel with hollow hexagonal honeycomb structure. The distribution of $\mathrm{C}, \mathrm{Fe}$, and $\mathrm{Ni}$ elements in EDS diagram (Fig. 3a") also shows that the $f$-FeNi has been successfully grafted on the surface of rGH skeleton, and the rGH@FeNi aerogel present hexagonal honeycomb and prismatic structures in cross and longitudinal sections, respectively. Therefore, the $f$-FeNi and rGO construct a more effective 3D conductive and magnetic path. As shown in Fig. 3b, b', the rGH@FeNi aerogel can maintain its morphology without obvious damage after the backfilling of epoxy resin. The fracture surfaces of rGH@ $\mathrm{FeNi} /$ epoxy composite still present the original regular hexagonal honeycomb and prismatic structures in cross and longitudinal sections, respectively. The construction of highly oriented hexagonal honeycomb structure is of great significance for the improvement of $\sigma$, EMI shielding and mechanical properties of the composites.

\subsection{Electrical Conductivities and EMI Shielding Performances of rGH@FeNi/Epoxy Composites}

Figure $4 \mathrm{a}$ is $\sigma$ of $\mathrm{rGO} / \mathrm{FeNi} /$ epoxy and $\mathrm{rGH} @ \mathrm{FeNi} /$ epoxy EMI shielding composites. With the same mass fraction of rGO and rGH (1.2 wt \%), the two kinds of composites both exhibit decreased $\sigma$ as the $f$-FeNi mass fraction increases. When the mass fraction of rGH@FeNi is $2.1 \mathrm{wt} \%$ (the mass fraction of $f$-FeNi is $0.9 \mathrm{wt} \%$ ), the $\sigma$ of $\mathrm{rGH} @ \mathrm{FeNi} / \mathrm{epoxy}$ composites is $38.7 \mathrm{~S} \mathrm{~m}^{-1}$, which is much higher than that of $\mathrm{rGO} / \mathrm{FeNi} / \mathrm{epoxy}$ composites with the same mass fraction. However, it is slightly lower than the $\sigma\left(40.2 \mathrm{~S} \mathrm{~m}^{-1}\right)$ of rGH/epoxy composites without $f$-FeNi. For rGO/FeNi/epoxy composites, the rGO tends to aggregate easily in the epoxy resin matrix during physical blending due to its high surface energy, resulting in the difficulty of forming perfect conductive path and relatively low $\sigma$. When rGO is constructed into $\mathrm{rGH}$ with the assistance of honeycomb template, the rGO forms an efficient 3D continuous conductive network inside the epoxy resin matrix, thus leading to the greatly increased $\sigma[27,45]$. As the mass fraction of magnetic $f$-FeNi 

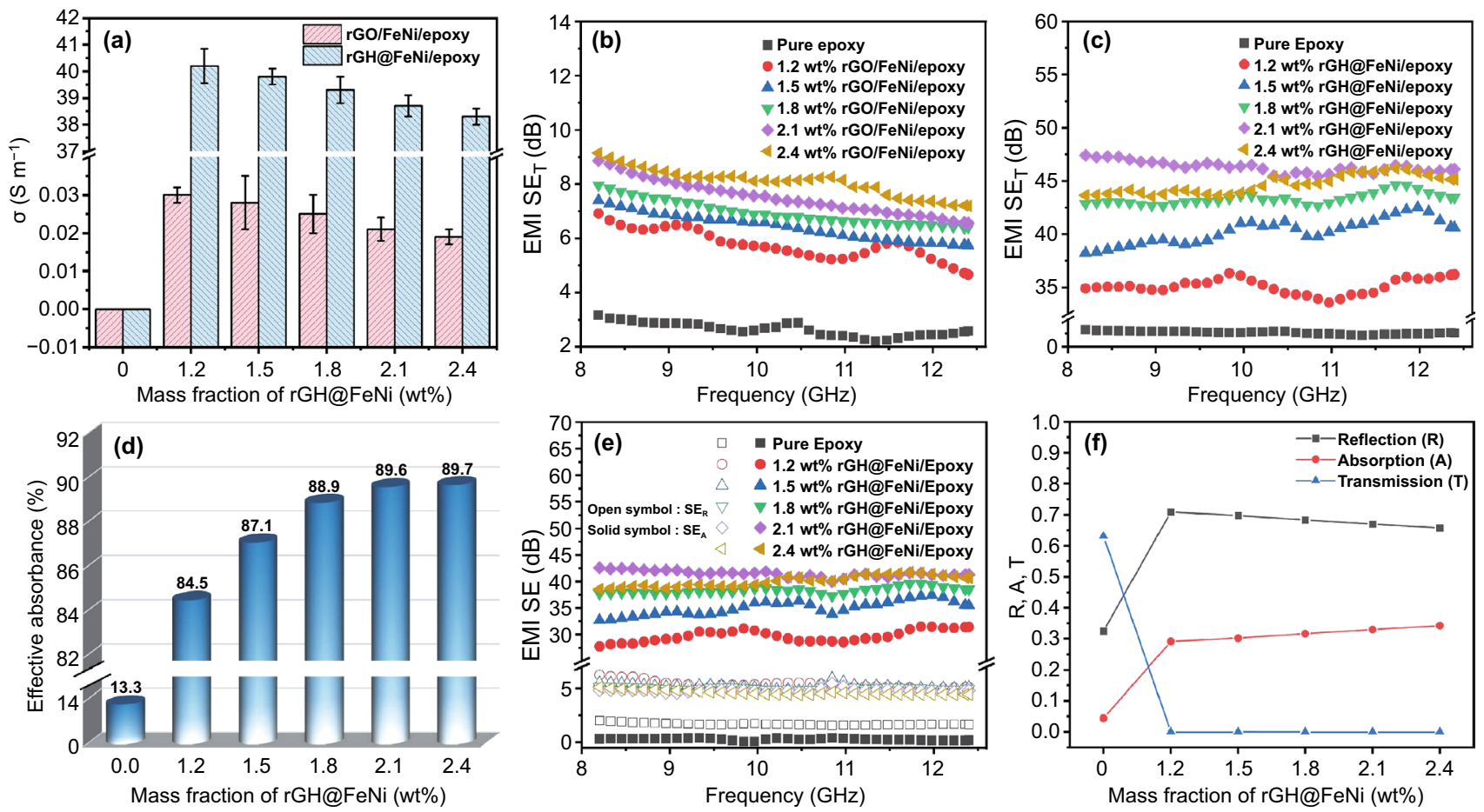

Fig. $4 \sigma$ of rGO/FeNi/epoxy and rGH@FeNi/epoxy composites (a), EMI SE $\mathrm{T}_{\mathrm{T}}$ of rGO/FeNi/epoxy composites (b), EMI SE $\mathrm{T}_{\mathrm{T}}$ (c), effective absorbance (d), EMI SE $\mathrm{A}_{\mathrm{A}}$ \& $\mathrm{SE}_{\mathrm{R}}(\mathbf{e})$ and $\mathrm{R}, \mathrm{A}$ and $\mathrm{T}$ coefficients (f) of $\mathrm{rGH} @ \mathrm{FeNi} /$ epoxy composites

increases, the contact resistance between rGH conductive networks gradually increases due to the intrinsic electrical insulation of $f$-FeNi, leading to the reduced $\sigma$ of rGH@ $\mathrm{FeNi} /$ epoxy composites to a certain extent.

Figure $4 \mathrm{~b}$, c shows the EMI $\mathrm{SE}_{\mathrm{T}}$ values of $\mathrm{rGO} / \mathrm{FeNi} /$ epoxy and rGH@FeNi/epoxy EMI shielding composites, respectively. With the same mass fraction of rGO and $\mathrm{rGH}$ (1.2 $\mathrm{wt} \%$ ), the EMI $\mathrm{SE}_{\mathrm{T}}$ of $\mathrm{rGO} / \mathrm{FeNi} /$ epoxy composites gradually increases as the $f$-FeNi mass fraction increases, while the that of rGH@FeNi/epoxy composites firstly increases and then decreases. When the mass fraction of $\mathrm{rGH} @ \mathrm{FeNi}$ is $2.1 \mathrm{wt} \%$ (the mass fraction of $f$ - $\mathrm{FeNi}$ is 0.9 $\mathrm{wt} \%$ ), the EMI $\mathrm{SE}_{\mathrm{T}}$ of $\mathrm{rGH} @ \mathrm{FeNi} /$ epoxy composites reach the maximum value of $46 \mathrm{~dB}$, which is 5.8 times of that of $\mathrm{rGO} / \mathrm{FeNi}$ /epoxy composites $(8 \mathrm{~dB})$ with same mass fraction. On the one hand, the honeycomb structure in rGH@ $\mathrm{FeNi} /$ epoxy composites constructs a highly effective 3D conductive rGH network inside the epoxy resin matrix, leading to the significantly increased $\sigma$ and thus improved ohmic loss of incident electromagnetic waves [46, 47]. On the other hand, the continuous 3D conductive/magnetic rGH network can enhance the multiple reflection and scattering of electromagnetic waves in $\mathrm{rGH} @ \mathrm{FeNi} /$ epoxy composites and extend the transmission path of electromagnetic waves, which contribute to the attenuation of electromagnetic waves and $\mathrm{EMI} \mathrm{SE}_{\mathrm{T}}$ of the composites [48, 49]. Meanwhile, the increasing mass fraction of $f$-FeNi can enhance the hysteresis loss of electromagnetic waves in the rGH@FeNi/epoxy composites. Nevertheless, as the mass fraction of $f$-FeNi further increases to $1.2 \mathrm{wt} \%$, the excessive $f$-FeNi is detrimental to the gelation of rGH and brings damage to the construction of rGH@FeNi continuous network to some extent (Fig. S3). Therefore, the EMI SE $\mathrm{T}_{\mathrm{T}}$ of $\mathrm{rGH} @ \mathrm{FeNi} /$ epoxy composites decreases slightly when the mass fraction of $\mathrm{rGH} @ \mathrm{FeNi}$ is $2.4 \mathrm{wt} \%$.

Figure $4 \mathrm{~d}$ is the electromagnetic wave effective absorbance of rGH@FeNi/epoxy EMI shielding composites (calculated by Eq. S9). It can be seen that with a constant mass fraction of $\mathrm{rGH}(1.2 \mathrm{wt} \%)$, the electromagnetic wave effective absorbance of $\mathrm{rGH} @ \mathrm{FeNi} /$ epoxy composites gradually increases as the mass fraction of $f$-FeNi increases. When the mass fraction of rGH@ $\mathrm{FeNi}$ is $2.1 \mathrm{wt} \%$ (the mass fraction of $f$-FeNi is $0.9 \mathrm{wt} \%$ ), the electromagnetic wave absorption rate of rGH@FeNi/epoxy composites is $89.6 \%$, which is higher than that of $\mathrm{rGH} / \mathrm{epoxy}$ composite without $f$-FeNi $(84.5 \%)$. This is because that the loading of $f$-FeNi enhances 
the hysteresis loss of rGH@FeNi/epoxy composites to electromagnetic waves due to the improved impedance matching between rGH 3D conductive skeleton and epoxy resin matrix, thus leading to the significantly increased effective absorbance of the composites [36, 39].

Figure $4 \mathrm{e}$ shows the absorpted shielding effectiveness $\left(\mathrm{SE}_{\mathrm{A}}\right)$ and reflected shielding effectiveness $\left(\mathrm{SE}_{\mathrm{R}}\right)$ of rGH@FeNi/epoxy EMI shielding composites in X-band. As can be seen, with the increase of $f$-FeNi mass fraction, the $\mathrm{SE}_{\mathrm{R}}$ of rGH@FeNi/epoxy composites remain at about $5 \mathrm{~dB}$ with the constant $\mathrm{rGH}$ mass fraction (1.2 $\mathrm{wt} \%$ ). The $\mathrm{SE}_{\mathrm{A}}$ and $\mathrm{SE}_{\mathrm{T}}$ show the same variation tendency, both of which firstly increase and then decrease with the increase of $f$-FeNi mass fraction. When the mass fraction of $\mathrm{rGH} @ \mathrm{FeNi}$ is $2.1 \mathrm{wt} \%$ (the mass fraction of $f$-FeNi is $0.9 \mathrm{wt} \%$ ), the $\mathrm{SE}_{\mathrm{A}}$ of $\mathrm{rGH} @ \mathrm{FeNi} /$ epoxy composites can reach $41 \mathrm{~dB}$. This is mainly attributed to the fact that the incorporation of $f$-FeNi can improve the impedance matching of composites and enhance the hysteresis loss of electromagnetic waves in composites, thus improving the $\mathrm{SE}_{\mathrm{A}}$ value. For practical application, the EMI shielding mechanism of rGH@FeNi/epoxy composites is evaluated by reflection (R), absorption (A) and transmission (T) coefficients (Eqs. S3-S5). As shown in Fig. 4f, the rGH@FeNi/epoxy composites with various $f$-FeNi mass fraction all show extremely low $\mathrm{T}$ coefficient. When the mass fraction of rGH@FeNi is $2.1 \mathrm{wt} \%$ (the mass fraction of $f$ - $\mathrm{FeNi}$ is $0.9 \mathrm{wt} \%$ ), the $\mathrm{T}$ coefficient of $\mathrm{rGH} @ \mathrm{FeNi} /$ epoxy EMI shielding composites is as low as only $2 \times 10^{-5}$, demonstrating that the incorporation of $f$-FeNi can significantly improve the EMI shielding performances. At the same time, the $\mathrm{R}$ value of $\mathrm{rGH} @ \mathrm{FeNi}$ /epoxy composites gradually decreases with the constant rGH mass fraction (1.2 wt $\%)$ and increased $f$-FeNi mass fraction. It is because that the incorporated $f$-FeNi can reduce $\sigma$ and increase the magnetism, which can improve the impedance matching between rGH@FeNi cellular network and external space. This results in the increased absorption and reduced reflection of electromagnetic waves on the surface of rGH@ $\mathrm{FeNi}$ /epoxy composites, and is beneficial to reducing the secondary pollution of electromagnetic waves $[50,51]$.

When the incident electromagnetic wave reaches the surface of rGH@FeNi/epoxy EMI shielding composites, some incident electromagnetic waves are reflected on the surface of rGH@FeNi/epoxy composites due to the impedance mismatch between external space and composites, while the rest electromagnetic waves enter the interior of $\mathrm{rGH} @ \mathrm{FeNi} /$ epoxy composites. First of all, when electromagnetic waves pass through the honeycomb wall of $\mathrm{rGH}$, the highly conductive $\mathrm{rGH}$ will generate induced current and cause ohmic losses of electromagnetic waves [22, 52]. Secondly, the existence of the honeycomb conductive/magnetic structure lengthens the transmission path of electromagnetic waves in the composites, leading to the enhanced attenuation of electromagnetic waves by multiple reflection and scattering [53]. Meanwhile, the hysteresis loss caused by the magnetic $f$-FeNi also contribute to the absorption of incident electromagnetic waves [54]. In addition, as the $\sigma$ of $\mathrm{rGH}$ is much higher than that of epoxy resin, there are different $\sigma$ values on the two sides of interfaces. Under the external electric field, the positive charges and negative charges accumulate in the rGH and epoxy resin sides respectively, thus resulting in the interface polarization loss $[55,56]$. Therefore, the multiple loss mechanism composed of ohmic loss, internal multiple reflections, hysteresis loss and interface polarization loss greatly improve the EMI shielding performance of rGH@FeNi/epoxy composites. The EMI shielding mechanism of rGH@FeNi/epoxy composites is shown in Fig. 5.

\subsection{Thermal Stabilities of the rGH@FeNi/epoxy Composites}

Figure 6a, a' show the thermal gravimetric analysis (TGA) and derivative thermogravimetric (DTG) curves of pure epoxy and rGH@FeNi/epoxy EMI shielding composites, respectively [57], with the corresponding characteristic data shown in Table 2. The heat-resistance index $\left(T_{\mathrm{HRI}}\right)$ is calculated by Eq. 1 to evaluate the long-term service temperature of polymer nanocomposites.

$T_{\text {Heat-resis } \tan \text { ceindex }}=0.49^{\prime}\left[T_{5}+0.6^{\prime}\left(T_{30}-T_{5}\right)\right]$

where $T_{5}$ and $T_{30}$ correspond to the decomposition temperatures of 5\% and $30 \%$ weight loss, respectively. It can be seen that the heat-resistance index $\left(T_{\mathrm{HRI}}\right)$ and temperature at the maximum decomposition rate $\left(T_{\mathrm{dmax}}\right)$ of pure epoxy are $173.5^{\circ} \mathrm{C}$ and $381.3^{\circ} \mathrm{C}$, respectively. The $T_{5}, T_{30}, T_{\mathrm{HRI}}$, and $T_{\mathrm{dmax}}$ of rGH@FeNi/epoxy composites are significantly improved with the increased FeNi mass fraction and constant $\mathrm{rGH}$ mass fraction $(1.2 \mathrm{wt} \%)$. When the mass fraction of $\mathrm{rGH} @ \mathrm{FeNi}$ is $2.1 \mathrm{wt} \%$ (the mass fraction of $\mathrm{FeNi}$ is 0.9 


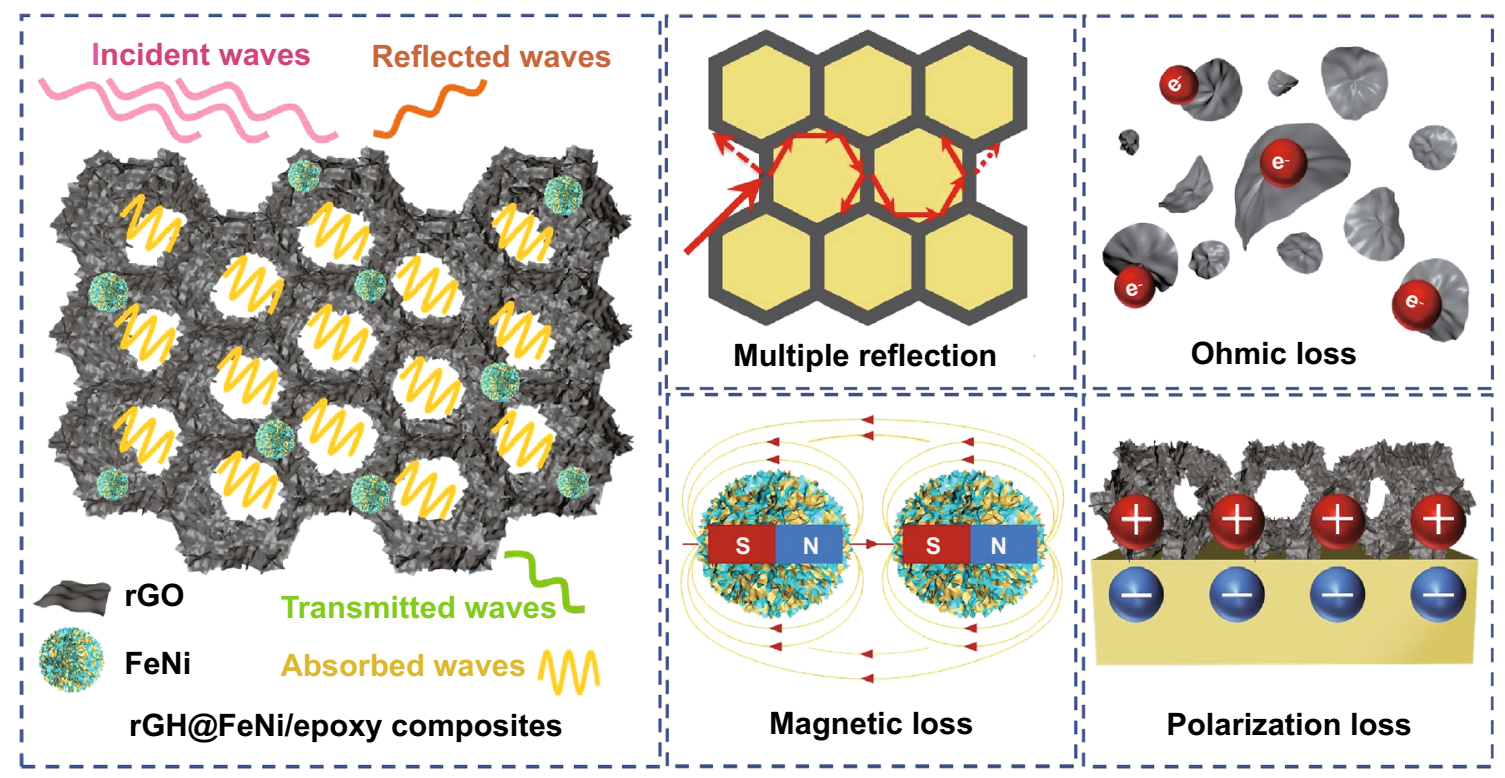

Fig. 5 EMI shielding mechanism of rGH@FeNi/epoxy composites
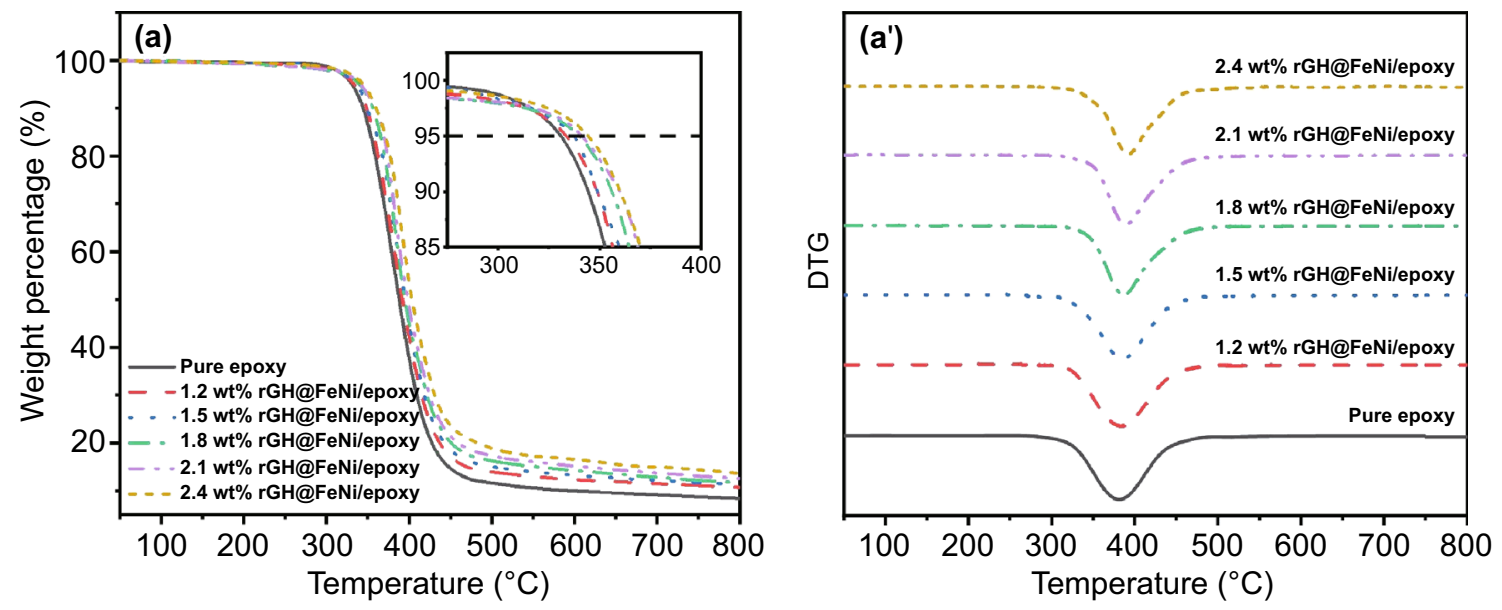

Fig. 6 TGA (a) and DTG (a') curves of the rGH@FeNi/epoxy composites

wt $\%$ ), the $T_{\mathrm{HRI}}$ and $T_{\mathrm{dmax}}$ of $\mathrm{rGH} @ \mathrm{FeNi}$ /epoxy composites can reach 179.1 and $389.0{ }^{\circ} \mathrm{C}$, respectively, which are 5.6 and $7.7{ }^{\circ} \mathrm{C}$ higher than those of pure epoxy, respectively. This is because that the incorporation of $f$-FeNi with excellent thermal stability can improve the heat resistance of rGH@FeNi/epoxy composites. In addition, the 3D honeycomb network structure formed by rGH@FeNi can effectively prevent the thermal degradation of rGH@FeNi/epoxy composites, slow down the thermal degradation rate, thus resulting the improved thermal stability $[58,59]$.

\subsection{Dynamic Mechanical Analysis of the rGH@FeNi/ epoxy Composites}

Figure 7a, a' shows the dynamic mechanical analysis (DMA) curves of rGH@FeNi/epoxy EMI shielding composites and their corresponding storage modulus $\left(E_{\mathrm{s}}\right)$ at the temperature of $40{ }^{\circ} \mathrm{C}$, respectively. It can be seen that the $E_{\mathrm{s}}$ of pure epoxy is $5800.2 \mathrm{MPa}$. With the constant mass fraction of rGH (1.2 wt $\%)$, the $E_{\mathrm{s}}$ of rGH@FeNi/ 
Table 2 Thermal characteristic data of the rGH@FeNi/epoxy composites

\begin{tabular}{lllll}
\hline Sample & $\begin{array}{l}\text { Weight loss } \\
\text { temperature } \\
\end{array}$ & $T_{\text {HRI }}\left({ }^{\circ} \mathrm{C}\right)$ & $T_{\text {dmax }}\left({ }^{\circ} \mathrm{C}\right)$ \\
\cline { 2 - 4 } & $T_{5}$ & $T_{30}$ & & \\
\hline Pure epoxy & 330.8 & 369.7 & 173.5 & 381.3 \\
1.2 wt\% rGH@FeNi/epoxy & 333.7 & 373.3 & 175.2 & 383.2 \\
1.5 wt\% rGH@FeNi/epoxy & 337.3 & 377.3 & 177.0 & 385.0 \\
1.8 wt\% rGH@FeNi/epoxy & 340.0 & 379.0 & 178.1 & 386.7 \\
2.1 wt\% rGH@FeNi/epoxy & 341.3 & 381.7 & 179.1 & 389.0 \\
2.4 wt\% rGH@FeNi/epoxy & 344.3 & 386.7 & 181.2 & 392.3 \\
\hline
\end{tabular}

epoxy composites first increase and then decrease with the increasing $f$-FeNi mass fraction. When the mass fraction of rGH@FeNi is $2.1 \mathrm{wt} \%$ (the mass fraction of $f$-FeNi is 0.9 wt\%), the rGH@FeNi/epoxy composites exhibit the largest $E_{\mathrm{s}}$ of $8296.2 \mathrm{MPa}$, which is $43 \%$ higher than that of pure epoxy. The related reason is that in incorporation of $f$-FeNi increases the surface roughness of $\mathrm{rGH} @ \mathrm{FeNi}$ aerogel, which can inhibit the activity of molecular chain segments of epoxy resin due to the interface binding effect, thus leading to the improved $E_{\mathrm{s}}[60,61]$. With the further increase of $f$-FeNi mass fraction $(2.4 \mathrm{wt} \%)$, the excessive
FeNi destroys the 3D honeycomb network structure of rGH@FeNi aerogels to some extent, resulting in the slight decrease of $E_{\mathrm{s}}$.

\section{Conclusions}

In conclusion, the rGH@FeNi/epoxy EMI shielding composites with regular 3D honeycomb structures were prepared by sacrificial template, freeze-drying and vacuum-assisted impregnation of epoxy resin. Benefitting from the construction of 3D honeycomb structure and electromagnetic synergistic effect, the rGH@FeNi/epoxy composites with a low rGH@FeNi mass fraction of $2.1 \mathrm{wt} \%$ (rGH and $f$-FeNi are 1.2 and $0.9 \mathrm{wt} \%$ respectively) exhibit a high EMI shielding effectiveness (EMI SE) of $46 \mathrm{~dB}$, which is 5.8 times of that ( $8 \mathrm{~dB}$ ) for $\mathrm{rGO} / \mathrm{FeNi} /$ epoxy composites with the same $\mathrm{rGO} / \mathrm{FeNi}$ mass fraction. Meanwhile, the rGH@FeNi/epoxy composites also possess excellent thermal stability ( $T_{\mathrm{HRI}}$ and $T_{\mathrm{dmax}}$ were 179.1 and $389.0^{\circ} \mathrm{C}$, respectively) and mechanical properties ( $E_{\mathrm{s}}$ was 8296.2 MPa). It is believed that the epoxy-based EMI shielding composites with comprehensive performances have great application potentials in consumer electronics, artificial intelligence and information security, etc.

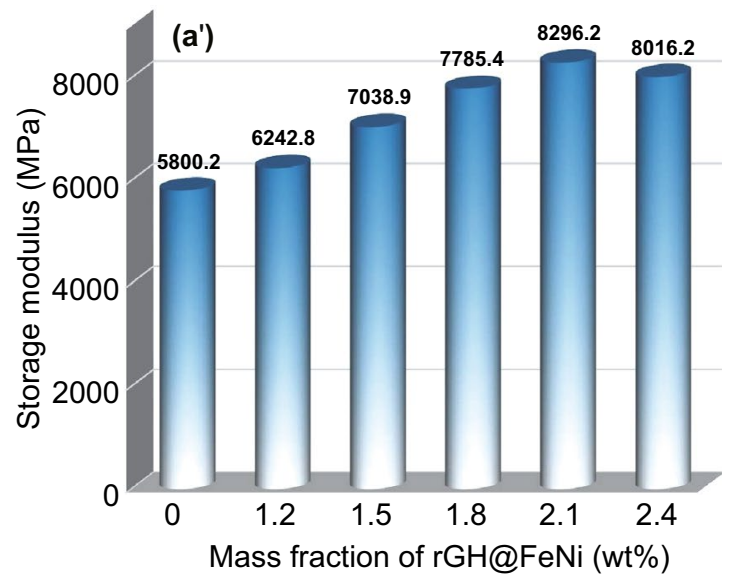

Fig. 7 DMA curves $(\mathbf{a})$ and $E_{\mathrm{s}}\left(\mathbf{a}^{\prime}\right)$ of the rGH@FeNi/epoxy composites 
Acknowledgements The authors are grateful for the supports from the National Natural Science Foundation of China (U21A2093 and 51903145), Natural Science Basic Research Plan for Distinguished Young Scholars in Shaanxi Province of China (2019JC11) and Fundamental Research Funds for the Central Universities (D5000210627). This work is also financially supported by Polymer Electromagnetic Functional Materials Innovation Team of Shaanxi Sanqin Scholars.

Funding Open access funding provided by Shanghai Jiao Tong University.

Open Access This article is licensed under a Creative Commons Attribution 4.0 International License, which permits use, sharing, adaptation, distribution and reproduction in any medium or format, as long as you give appropriate credit to the original author(s) and the source, provide a link to the Creative Commons licence, and indicate if changes were made. The images or other third party material in this article are included in the article's Creative Commons licence, unless indicated otherwise in a credit line to the material. If material is not included in the article's Creative Commons licence and your intended use is not permitted by statutory regulation or exceeds the permitted use, you will need to obtain permission directly from the copyright holder. To view a copy of this licence, visit http://creativecommons.org/licenses/by/4.0/.

Supplementary Information The online version contains supplementary material available at https://doi.org/10.1007/ s40820-022-00798-5.

\section{References}

1. Z. Xiang, Y. Shi, X. Zhu, L. Cai, W. Lu, Flexible and waterproof 2D/1D/0D construction of MXene-based nanocomposites for electromagnetic wave absorption, EMI shielding, and photothermal conversion. Nano-Micro Lett. 13, 150 (2021). https://doi.org/10.1007/s40820-021-00673-9

2. B. Anasori, M.R. Lukatskaya, Y. Gogotsi, 2D metal carbides and nitrides (MXenes) for energy storage. Nat. Rev. Mater. 2(2), 16098 (2017). https://doi.org/10.1038/natrevmats.2016. 98

3. J. Thomassin, C. Jérôme, T. Pardoen, C. Bailly, I. Huynen et al., Polymer/carbon based composites as electromagnetic interference (EMI) shielding materials. Mat. Sci. Eng. R 74, 211-232 (2013). https://doi.org/10.1016/j.mser.2013.06.001

4. Y. Zhang, Y. Yan, H. Qiu, Z. Ma, K. Ruan et al., A mini-review of MXene porous films:preparation, mechanism and application. J. Mater. Sci. Technol. 103, 42-49 (2022). https://doi.org/ 10.1016/j.jmst.2021.08.001

5. R. Sun, H. Zhang, J. Liu, X. Xie, R. Yang et al., Highly conductive transition metal carbide/carbonitride (MXene)@ polystyrene nanocomposites fabricated by electrostatic assembly for highly efficient electromagnetic interference shielding.
Adv. Funct. Mater. 27(45), 1702807 (2017). https://doi.org/ 10.1002/adfm.201702807

6. Y. Han, K. Ruan, J. Gu. Janus (BNNS/ANF)-(AgNWs/ANF) thermal conductivity composite films with superior electromagnetic interference shielding and joule heat performances. Nano Res. (2022). https://doi.org/10.1007/s12274-022-4159-z

7. J. Gao, J. Luo, L. Wang, X. Huang, H. Wang et al., Flexible, superhydrophobic and highly conductive composite based on non-woven polypropylene fabric for electromagnetic interference shielding. Chem. Eng. J. 364, 493-502 (2019). https:// doi.org/10.1016/j.cej.2019.01.190

8. L. Wang, Z. Ma, Y. Zhang, L. Chen, D. Cao et al., Polymerbased EMI shielding composites with $3 \mathrm{D}$ conductive networks: a mini-review. SusMat 1(3), 413-431 (2021). https:// doi.org/10.1002/sus2.21

9. A. Singh, A. Shishkin, T. Koppel, N. Gupta, A review of porous lightweight composite materials for electromagnetic interference shielding. Compos. Part B Eng. 149, 188-197 (2018). https://doi.org/10.1016/j.compositesb.2018.05.027

10. S. Huang, L. Wang, Y. Li, C. Liang, J. Zhang, Novel $\mathrm{Ti}_{3} \mathrm{C}_{2} \mathrm{~T}_{\mathrm{x}}$ MXene/epoxy intumescent fire-retardant coatings for ancient wooden architectures. J. Appl. Polym. Sci. 138(27), e50649 (2021). https://doi.org/10.1002/app.50649

11. G. Wang, X. Liao, F. Zou, P. Song, W. Tang et al., Flexible TPU/MWCNTs/BN composites for frequency-selective electromagnetic shielding and enhanced thermal conductivity. Compos. Commun. 28, 100953 (2021). https://doi.org/10. 1016/j.coco.2021.100953

12. L. Kong, X. Yin, H. Xu, X. Yuan, T. Wang et al., Powerful absorbing and lightweight electromagnetic shielding CNTs/ RGO composite. Carbon 145, 61-66 (2019). https://doi.org/ 10.1016/j.carbon.2019.01.009

13. M. Layani, A. Kamyshny, S. Magdassi, Transparent conductors composed of nanomaterials. Nanoscale 6(11), 5581-5591 (2014). https://doi.org/10.1039/C4NR00102H

14. Q. Wei, S. Pei, X. Qian, H. Liu, Z. Liu et al., Superhigh electromagnetic interference shielding of ultrathin aligned pristine graphene nanosheets film. Adv. Mater. 32(14), 1907411 (2020). https://doi.org/10.1002/adma.201907411

15. Z. Yu, T. Dai, S. Yuan, H. Zou, P. Liu, Electromagnetic interference shielding performance of anisotropic polyimide/ graphene composite aerogels. ACS Appl. Mater. Interfaces 12(27), 30990-31001 (2020). https://doi.org/10.1021/acsami. 0c07122

16. H. Zhang, Q. Yan, W. Zheng, Z. He, Z. Yu, Tough graphenepolymer microcellular foams for electromagnetic interference shielding. ACS Appl. Mater. Interfaces 3(3), 918-924 (2011). https://doi.org/10.1021/am200021v

17. H. Pang, L. Xu, D.X. Yan, Z.M. Li, Conductive polymer composites with segregated structures. Prog. Polym. Sci. 39(11), 1908-1933 (2014). https://doi.org/10.1016/j.progp olymsci.2014.07.007

18. M.A. Saleh, U. Sundararaj, A review of vapor grown carbon nanofiber/polymer conductive composites. Carbon 47(1), 2-22 (2009). https://doi.org/10.1016/j.carbon.2008.09.039 
19. Y. Ma, Y. Chen, Three-dimensional graphene networks: synthesis, properties and applications. Natl. Sci. Rev. 2(1), 40-53 (2015). https://doi.org/10.1093/nsr/nwu072

20. Z. Chen, W. Ren, L. Gao, B. Liu, S. Pei et al., Three-dimensional flexible and conductive interconnected graphene networks grown by chemical vapour deposition. Nat. Mater. 10(6), 424-428 (2011). https://doi.org/10.1038/nmat3001

21. T. Ma, H. Ma, K. Ruan, X. Shi, H. Qiu et al., Thermally conductive polylactic acid composites with superior electromagnetic shielding performances via 3D printing technology. Chinese J. Polym. Sci. (2022). https://doi.org/10.1007/ s10118-022-2673-9

22. P. Sawai, P.P. Chattopadhaya, S. Banerjee, Synthesized reduce graphene oxide (rGO) filled polyetherimide based nanocomposites for EMI shielding applications. Mater. Today Proc. 5(3), 9989-9999 (2018). https://doi.org/10. 1016/j.matpr.2017.10.197

23. V. Eswaraiah, V. Sankaranarayanan, S. Ramaprabhu, Functionalized graphene-PVDF foam composites for EMI shielding. Macromol. Mater. Eng. 296(10), 894-898 (2011). https://doi.org/10.1002/mame.201100035

24. D. Yan, H. Pang, B. Li, R. Vajtai, L. Xu et al., Structured reduced graphene oxide/polymer composites for ultra-efficient electromagnetic interference shielding. Adv. Funct. Mater. 25(4), 559-566 (2015). https://doi.org/10.1002/adfm. 201403809

25. C. Liang, H. Qiu, Y. Han, H. Gu, P. Song et al., Superior electromagnetic interference shielding 3D graphene nanoplatelets/reduced graphene oxide foam/epoxy nanocomposites with high thermal conductivity. J. Mater. Chem. C 7(9), 2725-2733 (2019). https://doi.org/10.1039/C8TC05955A

26. P. Song, B. Liu, H. Qiu, X. Shi, D. Cao et al., MXenes for polymer matrix electromagnetic interference shielding composites: a review. Compos. Commun. 24, 100653 (2021). https://doi.org/10.1016/j.coco.2021.100653

27. Z. Ma, X. Zhou, W. Deng, D. Lei, Z. Liu, 3D porous MXene $\left(\mathrm{Ti}_{3} \mathrm{C}_{2}\right)$ /reduced graphene oxide hybrid films for advanced lithium storage. ACS Appl. Mater. Interfaces 10(4), 36343643 (2018). https://doi.org/10.1021/acsami.7b17386

28. P. Song, C. Liang, L. Wang, H. Qiu, H. Gu et al., Obviously improved electromagnetic interference shielding performances for epoxy composites via constructing honeycomb structural reduced graphene oxide. Compos. Sci. Technol. 181, 107698 (2019). https://doi.org/10.1016/j.compscitech. 2019.107698

29. Y. Bhattacharjee, D. Chatterjee, S. Bose, Core-multishell heterostructure with excellent heat dissipation for electromagnetic interference shielding. ACS Appl. Mater. Interfaces 10(36), 30762-30773 (2018). https://doi.org/10.1021/acsami.8b10819

30. H. Cheng, S. Wei, Y. Ji, J. Zhai, X. Zhang et al., Synergetic effect effect of $\mathrm{Fe}_{3} \mathrm{O}_{4}$ nanoparticles and carbon on flexible poly (vinylidence fluoride) based films with higher heat dissipation to improve electromagnetic shielding. Compos. Part A Appl. Sci. Manuf. 121, 139-148 (2019). https://doi.org/ 10.1016/j.compositesa.2019.03.019
31. H. Zhang, G. Zhang, J. Li, X. Fan, Z. Jing et al., Lightweight, multifunctional microcellular PMMA/ $/ \mathrm{Fe}_{3} \mathrm{O}_{4} @$ MWCNTs nanocomposite foams with efficient electromagnetic interference shielding. Compos. Part A Appl. Sci. Manuf. 100, 128-138 (2017). https://doi.org/10.1016/j. compositesa.2017.05.009

32. R. Kumar, A.V. Alaferdov, R.K. Singh, A.K. Singh, J. Shah et al., Self-assembled nanostructures of 3D hierarchical faceted-iron oxide containing vertical carbon nanotubes on reduced graphene oxide hybrids for enhanced electromagnetic interface shielding. Compos. Part B Eng. 168, 66-76 (2019). https://doi.org/10.1016/j.compositesb.2018.12.047

33. H. Liu, C. Liang, J. Chen, Y. Huang, F. Cheng et al., Novel $3 \mathrm{D}$ network porous graphene nanoplatelets/ $\mathrm{Fe}_{3} \mathrm{O}_{4} /$ epoxy nanocomposites with enhanced electromagnetic interference shielding efficiency. Compos. Sci. Technol. 169, 103-109 (2019). https://doi.org/10.1016/j.compscitech.2018.11.005

34. K. Sushmita, T.V. Menon, S. Sharma, A.C. Abhyankar, G. Madras et al., Mechanistic insight into the nature of dopants in graphene derivatives influencing electromagnetic interference shielding properties in hybrid polymer nanocomposites. J. Phys. Chem. C 123(4), 2579-2590 (2019). https:// doi.org/10.1021/acs.jpcc.8b10999

35. A. Dong, Z. Zhiyi, W. Yanhui, C. Shuaishuai, L. Yaqing, The distinctly enhanced electromagnetic wave absorption properties of $\mathrm{FeNi} / \mathrm{rGO}$ nanocomposites compared with pure FeNi alloys. J. Supercond. Nov. Magn. 32(2), 385-392 (2019). https://doi.org/10.1007/s10948-018-4681-0

36. J. Li, L. Wang, D. Zhang, Y. Qu, G. Wang et al., Reduced graphene oxide modified mesoporous FeNi alloy/carbon microspheres for enhanced broadband electromagnetic wave absorbers. Mater. Chem. Front. 1(9), 1786-1794 (2017). https://doi.org/10.1039/C7QM00067G

37. P. Song, H. Qiu, L. Wang, X. Liu, Y. Zhang et al., Honeycomb structural rGO-MXene/epoxy nanocomposites for superior electromagnetic interference shielding performance. Sustain. Mater. Technol. 24, e00153 (2020). https:// doi.org/10.1016/j.susmat.2020.e00153

38. A.E. Deen, M.E. Newehy, C. Kim, N. Barakat, Nitrogendoped, FeNi alloy nanoparticle-decorated graphene as an efficient and stable electrode for electrochemical supercapacitors in acid medium. Nanoscale Res. Lett. 10(1), 104 (2015). https://doi.org/10.1186/s11671-015-0778-6

39. F. Ren, D. Song, Z. Li, L. Jia, Y. Zhao et al., Synergistic effect of graphene nanosheets and carbonyl iron-nickel alloy hybrid filler on electromagnetic interference shielding and thermal conductivity of cyanate ester composites. J. Mater. Chem. C 6(6), 1476-1486 (2018). https://doi.org/10.1039/ C7TC05213H

40. Y. Yao, S. Miao, S. Liu, L.P. Ma, H. Sun et al., Synthesis, characterization, and adsorption properties of magnetic $\mathrm{Fe}_{3} \mathrm{O}_{4} @$ graphene nanocomposite. Chem. Eng. J. 184, 326-332 (2012). https://doi.org/10.1016/j.cej.2011.12.017

41. M. Strankowski, D. Włodarczyk, Ł Piszczyk, J. Strankowska, Polyurethane nanocomposites containing reduced graphene 
oxide, FTIR, Raman, and XRD studies. J. Spectrosc. (2016). https://doi.org/10.1155/2016/7520741

42. X. Wang, J. Shu, X. He, M. Zhang, X. Wang et al., Green approach to conductive PEDOT:PSS decorating magneticgraphene to recover conductivity for highly efficient Absorption. ACS Sustain. Chem. Eng. 6(11), 14017-14025 (2018). https://doi.org/10.1021/acssuschemeng.8b02534

43. X. Yang, S. Fan, Y. Li, Y. Guo, K. Ruan et al., Copper nanowires/thermally annealed graphene aerogel/epoxy nanocomposites with excellent thermal conductivities and outstanding electromagnetic interference shielding effectiveness. Compos. Part A Appl. Sci. Manuf. 128, 105670 (2020). https://doi.org/ 10.1016/j.compositesa.2019.105670

44. J. Yang, E. Zhang, X. Li, Y. Zhang, J. Qu et al., Cellulose/ graphene aerogel supported phase change composites with high thermal conductivity and good shape stability for thermal energy storage. Carbon 98, 50-57 (2016). https://doi.org/10. 1016/j.carbon.2015.10.082

45. Y. Yue, N. Liu, Y. Ma, S. Wang, W. Liu et al., Highly selfhealable 3D microsupercapacitor with MXene-graphene composite aerogel. ACS Nano 12(5), 4224-4232 (2018). https:// doi.org/10.1021/acsnano.7b07528

46. Y. Chen, H.B. Zhang, Y.B. Yang, M. Wang, A.Y. Cao et al., High-performance epoxy nanocomposites reinforced with three-dimensional carbon nanotube sponge for electromagnetic interference shielding. Adv. Funct. Mater. 26(3), 447455 (2016). https://doi.org/10.1002/adfm.201503782

47. X. Li, X. Li, K. Liao, P. Min, T. Liu et al., Thermally annealed anisotropic graphene aerogels and their electrically conductive epoxy composites with excellent electromagnetic interference shielding efficiencies. ACS Appl. Mater. Interfaces 8(48), 33230-33239 (2016). https://doi.org/10.1021/acsami.6b12295

48. Y. Du, X. Kan, F. Yang, L. Gan, U. Schwingenschlogl, MXene/ graphene heterostructures as high-performance electrodes for Li-ion batteries. ACS Appl. Mater. Interfaces 10(38), 3286732873 (2018). https://doi.org/10.1021/acsami.8b10729

49. J. Fu, J. Yun, S. Wu, L. Li, L. Yu et al., Architecturally robust graphene-encapsulated MXene $\mathrm{Ti}_{2} \mathrm{CT}_{\mathrm{x}} @$ polyaniline composite for high-performance pouch-type asymmetric supercapacitor. ACS Appl. Mater. Interfaces 10(40), 34212-34221 (2018). https://doi.org/10.1021/acsami.8b10195

50. H. Duan, H. Zhu, J. Gao, D.X. Yan, K. Dai et al., Asymmetric conductive polymer composite foam for absorption dominated ultra-efficient electromagnetic interference shielding with extremely low reflection characteristics. J. Mater. Chem. A 8, 9146-9159 (2020). https://doi.org/10.1039/D0TA01393E

51. A. Sheng, Y. Yang, W. Ren, H. Duan, B. Liu et al., Ground tire rubber composites with hybrid conductive network for efficiency electromagnetic shielding and low reflection. J. Mater. Sci. Mater. Electron. 30(15), 14669-14678 (2019). https://doi.org/10.1007/s10854-019-01838-4

52. C. Liang, Z. Gu, Y. Zhang, Z. Ma, H. Qiu et al., Structural design strategies of polymer matrix composites for electromagnetic interference shielding: a review. Nano-Micro Lett. 13, 181 (2021). https://doi.org/10.1007/s40820-021-00707-2

53. A. Iqbal, P. Sambyal, C.M. Koo, 2D MXenes for electromagnetic shielding: a review. Adv. Funct. Mater. 30(47), 2000883 (2020). https://doi.org/10.1002/adfm.202000883

54. Y. Zhang, K. Ruan, J. Gu, Flexible sandwich-structured electromagnetic interference shielding nanocomposite films with excellent thermal conductivities. Small 17(42), 2101951 (2021). https://doi.org/10.1002/smll.202101951

55. M. Han, C.E. Shuck, R. Rakhmanov, D. Parchment, B. Anasori et al., Beyond $\mathrm{Ti}_{3} \mathrm{C}_{2} \mathrm{~T}_{\mathrm{x}}$ : MXenes for electromagnetic interference shielding. ACS Nano 14(4), 5008-5016 (2020). https:// doi.org/10.1021/acsnano.0c01312

56. Y. Bhattacharjee, I. Arief, S. Bose, Recent trends in multilayered architectures towards screening electromagnetic radiation: challenges and perspectives. J. Mater. Chem. C 5(30), 7390-7403 (2017). https://doi.org/10.1039/C7TC02172K

57. X. Zhong, X. Yang, K. Ruan, J. Zhang, H. Zhang et al., Discotic liquid crystal epoxy resins integrating intrinsic high thermal conductivity and intrinsic flame retardancy. Macromol. Rapid Commun. 43(1), 2100580 (2021). https://doi.org/10. 1002/marc. 202100580

58. Y. Zou, L. Fang, T. Chen, M. Sun, C. Lu et al., Near-infrared light and solar light activated self-healing epoxy coating having enhanced properties using MXene flakes as multifunctional fillers. Polymers 10(5), 474 (2018). https://doi.org/10. 3390/polym 10050474

59. R. Kang, Z. Zhang, L. Guo, J. Cui, Y. Chen et al., Enhanced thermal conductivity of epoxy composites filled with 2D transition metal carbides (MXenes) with ultralow loading. Sci. Rep. 9(1), 9135 (2019). https://doi.org/10.1038/ s41598-019-45664-4

60. S. Chhetri, N.C. Adak, P. Samanta, N.C. Murmu, S.K. Srivastava et al., Synergistic effect of $\mathrm{Fe}_{3} \mathrm{O}_{4}$ anchored $\mathrm{N}$-doped $\mathrm{rGO}$ hybrid on mechanical, thermal and electromagnetic shielding properties of epoxy composites. Compos. Part B Eng. 166, 371-381 (2019). https://doi.org/10.1016/j.compositesb.2019. 02.036

61. H. Zhang, L. Wang, A. Zhou, C. Shen, Y. Dai et al., Effects of 2-D transition metal carbide $\mathrm{Ti}_{2} \mathrm{CT}_{\mathrm{x}}$ on properties of epoxy composites. RSC Adv. 6(90), 87341-87352 (2016). https:// doi.org/10.1039/C6RA14560D 